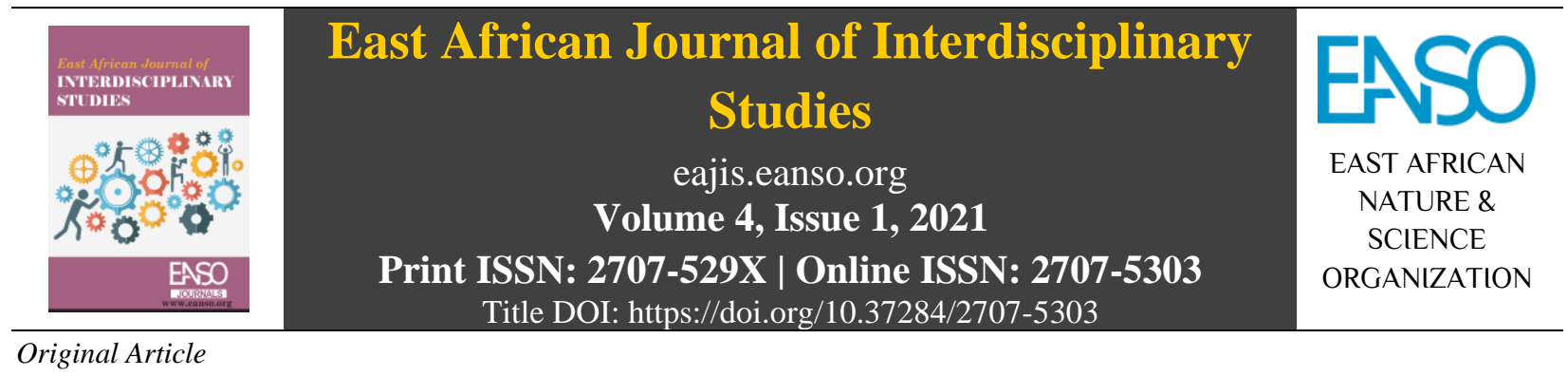

\title{
Psychosocial Challenges Facing Orphaned Children and Caregivers in Tanzanian Institutionalized Orphanage Centres.
}

\author{
Theophil Christopher ${ }^{1} \&$ Dr. Mary Atanas Mosha, PhD ${ }^{1^{*}}$ \\ ${ }^{1}$ Jordan University College, P.O. Box1878, Morogoro, Tanzania. \\ 2*Senior Lecturer, Kampala International University in Tanzania, P.O. Box9790, Dar es Salaam Tanzania \\ * ORCID: https://orcid.org/0000-0002-1669-9886; Author for Correspondence Email: dr.marymosha@ gmail.com
}

Article DOI: https://doi.org/10.37284/eajis.4.1.444

\section{Date Published: ABSTRACT}

22 October 2021 This study investigated psychosocial challenges facing orphaned children and caregivers as well as possible intervention strategies that could be adopted to Keywords: mitigate these challenges in the institutionalised orphaned children centres in Ubungo Municipal, Dar es Salaam. The study used a qualitative research

Psychosocial approach and a descriptive research design. A purposive sampling technique was

Challenges, Orphaned Children, employed to select six orphanage centres. The study had a sample of 67 participants including children receiving orphanage care at the institutionalised Orphanage Centres, orphaned children centres, caregivers and directors of the centres who were selected through purposive sampling technique. Data were collected using inOrphanage Services, depth interviews and a non-observation method and were sorted and coded based

Caregivers. on themes and presented according to the research questions. Thematic analysis was used in qualitative data. Findings from the study revealed that orphaned children were supported with various services including food, clothes, accommodation, health services, spiritual and educational support, life skills, sports and games. It was found further that the orphans were faced with a lack of adequate health facilities including health insurance coverage, educational materials, sports gear and in some centres inadequate clean and safe water. Caregivers lack counselling knowledge and skills. Therefore, the study recommends community participation in providing care to orphaned children and equipping caregivers with relevant knowledge and skills to perform their duties competently.

\section{APA CITATION}

Christopher, T., \& Mosha, M. A. (2021). Psychosocial Challenges Facing Orphaned Children and Caregivers in Tanzanian Institutionalized Orphanage Centres East African Journal of Interdisciplinary Studies, 4(1), 1-14. https://doi.org/10.37284/eajis.4.1.444.

\section{CHICAGO CITATION}

Theophil Christopher, and Mary Atanas Mosha. 2021. "Psychosocial Challenges Facing Orphaned Children and Caregivers in Tanzanian Institutionalized Orphanage Centres". East African Journal of Interdisciplinary Studies 4 (1), 1-14. https://doi.org/10.37284/eajis.4.1.444.

1| This work is licensed under a Creative Commons Attribution 4.0 International License. 


\section{HARVARD CITATION}

Christopher, T., and Mosha, M. A. (2021) "Psychosocial Challenges Facing Orphaned Children and Caregivers in Tanzanian Institutionalized Orphanage Centres”, East African Journal of Interdisciplinary Studies, 4(1), pp. 1-14. doi: 10.37284/eajis.4.1.444.

\section{IEEE CITATION}

T. Christopher, and M. A. Mosha, "Psychosocial Challenges Facing Orphaned Children and Caregivers in Tanzanian Institutionalized Orphanage Centres”, EAJIS, vol. 4, no. 1, pp. 1-14, Oct. 2021.

\section{MLA CITATION}

Theophil Christopher, and Mary Atanas Mosha. "Psychosocial Challenges Facing Orphaned Children and Caregivers in Tanzanian Institutionalized Orphanage Centres”. East African Journal of Interdisciplinary Studies, Vol. 4, no. 1, Oct. 2021, pp. 1-14, doi:10.37284/eajis.4.1.444.

\section{INTRODUCTION}

Child care in Tanzania takes place in various environments that include different configurations of families and child care institutions. It is noted that due to the HIV epidemic in many countries including Tanzania, increasing numbers of children in Sub-Saharan African (SSA) countries are being taken care of in orphanages (Daniel and Rukundo, 2016). These orphanages have in turn become overwhelmed by the number of children in need of psychosocial support and care (Msoka \& Holroyd, 2018). Psychosocial support is categorised as instrumental support, emotional support, and informational support that includes appraisal support (REPSSI, 2016; Schenk et al., 2010). Van Dyk (2007) and Evangelou et al. (2009) elaborated that psychosocial wellbeing occurs when the internal and external needs of children are met and recipients become physically, mentally and socially healthy.

When children lose their parents and enter orphanage care, they suffer a series of bereavements (Atwine et al., 2005; Evangelou et al., 2009; Nyawasha and Chipunza, 2012). For instance, Larose et al. (2005), Beek and Schofield (2004), Van Dyk (2007) and REPSSI (2016) established that social conditions related to orphan hood influence the psychological wellbeing of children with regard to their need to make new and rapid social and psychological adjustments. In addition to that, orphaned children are affected psychologically related to the trauma and associated hardships they experience.

Researchers Stroebeet al. (2016) determined that bereavement is distressing and has a diverse effect on children's affective, cognitive, social, behavioural and physical status with physiological and somatic manifestations. Larose et al. (2005) and Boutin (2006) contend that the majority of children being cared for in institutions experience intense psychological problems due to their new status. In the context of children's life ways, psycho-social wellbeing includes emotional or psychological wellbeing as well as social and collective wellbeing. Psychosocial being is similar to a quality life since they both include emotional, social and physical wellbeing (Eiroa Orosa, 2020). According to Fitzgerald and co-workers (2019), psychosocial wellbeing can be measured by capturing three aspects which are psychological, social and spiritual aspects. These aspects are based on cognitive and emotional judgments that individuals make about their lives.

Children need various types of support ranging from those things necessary for survival, such as food and health care, to those interventions that will provide a better quality of life in the future such as education, psychosocial support and economic selfsufficiency (Stover et al., 2005). Some argue that a holistic program to support children should include all necessary elements such as food, health care, education, clothes, shoes, bedding, psychosocial support and economic self-sufficiency among the caregivers, stakeholders, school community, governmental and non-governmental organisations. Others hold that some of these elements are not "essential" or far exceed the situation of most children living in poor households with both parents. In recent decades, the image of the orphan has come to embody child vulnerability in subSaharan Africa. Estimates of the alarming numbers of children being orphaned by AIDS-related deaths in the region raised international concern (Abebe \& Aase, 2007). Moreover, Yang et al. (2011), Kamali

$2 \mid$ This work is licensed under a Creative Commons Attribution 4.0 International License. 
et al. (1996) and Golding et al. (2006) contend that when orphaned children are placed in institutions and move away from their fellow siblings and friends, they develop anger and depression, which in turn lowers their concentration in school and hence results in poor performance.

\section{BACKGROUND}

There are nearly 140 million orphan children worldwide who have lost one or both parents (UNICEF, 2017). Among them, 61 million are in Asia, 52 million are in Africa (among them, 45 million are in Sub-Saharan Africa), 10 million are in Latin America as well as the Caribbean, and 7.3 million are in Eastern Europe and Central Asia. Similarly, it is estimated that about 2.6 million children in Tanzania are orphaned due to Human Immunodeficiency Virus (HIV) and Acquired Immune Deficiency Syndrome (AIDS). Loss of parents means loss of love, protection, care and support (Vedasto, 2015; Makuu, 2019). Huynh et al. (2019) reported that leaders at the global level and national level are struggling to find solutions on caring for the estimated 140 million orphaned children worldwide. Leaders are struggling because there are negative impacts associated with being orphans including depression, anger, anxiety, and feeling of sadness (Huynh et al., 2019).

UNICEF (2010) divides children accommodated in the orphanages into four mutually exclusive categories for analysis purposes. First, there are those known as maternal orphans who include children under the age of 18 whose biological mothers have died. Second, there are paternal orphans who include children under the age of 18 whose biological fathers have died. Third, there are those known as double orphans, who include children under the age of 18 whose biological mothers and fathers have both died. Further, there are those orphans due to AIDS that have lost one or both their guardians including close relatives and foster parents.

In Sub-Saharan Africa (SSA), Huynh et al. (2019) noted the problem of poverty to spread fast into the areas where orphan children live and stop them from security and structures that support children to grow, flourish, and develop. Hence, orphans need living environments that assure them security and promote their psychosocial wellbeing. For instance, Kayombo, Mwambo and Masilla (2005) found that children need psychosocial support to be aware of cultural practices, beliefs and rituals. To support such children, culture is the hinge of the pivotal point because it helps to store connectedness, values, belonging, knowledge, and traditional practices regarded to be the essential elements of the general child wellbeing.

Tanzania, like any other country in Sub-Saharan countries, is faced with the challenges of having orphans and vulnerable children. The government is concerned with child care and protection. The situation of orphans in Tanzania is exacerbated by poverty since parents or caretakers from extended families do not generate adequate incomes for survival. They lack the necessary resources to ensure their sustainable wellbeing. It is argued that Tanzanian children are struggling in terms of care, security and protection. Orphaned and vulnerable children have been pushed into critical discrimination, stigmatisation, abuse and general neglect (Makuu, 2019).

Children in orphanage resident care face many difficulties such as poverty, poor physical health, attachment disorders, inadequate social skills, and mental health difficulties. Added to this is the loss of one or both parents, which is difficult for the children. It results in psychological problems, and the effects may not manifest until many years afterwards (Atwine et al., 2012). Orphans and vulnerable children are subjected to multiple ongoing stressful and traumatic life events such as abuse, neglect, parental loss, sexual abuse, among others (Murray et al., 2013).

Many orphans who feel rejected and despair need social support. Such social support is more than a matter of social relationships or social contact: rather it implies providing emotional and material resources (Brannon, 2008). Therefore, the number of acquaintances a person has or the number of people with which he/she associates with will not be a good indicator of social support. Multiple studies have revealed that orphans suffer higher levels of psychosocial distress than their non-orphan peers. In particular, maternal and double orphans are more likely to experience behavioural and emotional difficulties, suffer abuse, and report lower rates of 
trusting relationships with caregivers (Baaroy \& Webb, 2008).

There is an increasing number of orphans in Tanzania. Statistics have influenced the establishment of different institutions to protect the wellbeing of orphaned children. Most of the institutions are owned by government agencies, non-governmental organisations, private sectors, civil societies and religious-based organisations (Makuu, 2017). Such institutions intend to provide care and support to children. However, it has been pointed out that most institutions perform their functions under scarce resources (Caserta, 2017). Due to such shortages, orphaned children do not get effective psycho-social support (REPPSI, 2016). Therefore, this study investigated psychosocial challenges facing orphaned children and caregivers in the selected institutions.

The objective of the study was to examine psychosocial challenges facing orphaned children and caregivers in their various settings. It seemed important to conduct a systematic investigation into the actual problems. The study was guided by three questions:

- What are psychosocial services provided to the orphaned children in the institutionalised centres?

- What are the psychosocial challenges facing orphaned children and caregivers in the selected centres?

- What can be done to minimise the existing challenges?

\section{THEORETICAL PERSPECTIVE}

The study is based on Social Network Theory (SNT). Social Network Theory was developed by Scott (1991) from the premises of social disorganisation theory. The central theme of this theory is social ties. The main argument of this theory is that the socially disorganised areas lack social ties that eventually trigger informal mechanisms for social controls. According to this theory, the formation and maintenance of informal social controls require neighbourhoods to have strong social ties that connect residents. Social ties are measured in terms of quantity and content.
Social Network Theory operates on many levels, from the family level to the national level. The social network determines problem-solving mechanisms, operations of the organisations and the way through which individuals succeed in achieving their goals. This study utilises a social tier to describe the way communities, through orphanage centres, identify and solve various challenges facing orphaned children residing in institutionalised orphanages. Generally, the theory describes the role of society and the impact of societal responses on the state of orphaned and vulnerable children, especially on the roles of children's homes in addressing the needs of the orphaned and vulnerable children.

\section{REVIEW OF RELATED LITERATURE}

The problem of being an orphan is not a new phenomenon. It existed even during the communalism era where orphans were taken care of, protected and supported by close relatives. Nowadays, the problem is highly pronounced due to the increase in the number of orphans due to HIV/AIDS and other factors. Much attention has been paid at the national and international levels, where international agencies, non-governmental organisations and religious institutions are taking the responsibility of caring, supporting and protecting orphans including vulnerable children (Ntuli et al., 2020).

\section{Care Practices and Support to Orphanage Centres}

Management is required at the centres for planning, organising, leading and controlling affairs of the orphanage centres. For that matter, managers and caregivers are supposed to have management skills to ensure proper coordination and leading. Most centres have caregivers who take care of the orphans. They are the more influential on the children's life ways because they interact daily with the orphan children (Ismail et al., 2018). For instance, research by Mears et al. (2011) found that child care centres provide support to orphans in the following areas: psychosocial as well as material support, health care, education support and protection of children from gender discrimination, abuse and labour exploitation. However, the overall living condition in most of the surveyed orphanages

4| This work is licensed under a Creative Commons Attribution 4.0 International License. 
was poor and health care was inadequate in some orphanages. Besides, there were indications that access to food was limited and quality of care was substandard due to limited financial resources, lack of supervision, and minimal awareness of children's development issues (Makuu, 2017).

\section{Factors Leading to Orphans}

Children become orphans due to health issues such as HIV/AIDS and poverty where parents fail to support the children, thereby become orphans and vulnerable children (Pillay, 2016). According to the World Bank (2004), vulnerable children are children experiencing negative outcomes such as loss of their education, sickness and malnourishment at higher rates than their peers. They are characterised into the following six categories: street children, children in the worst form of child labour, children affected by armed conflicts, children affected by HIV/AIDS, children living with disabilities and local OVC groups.

Other factors like civil wars, terrorism, natural calamities and other diseases such as Ebola and Malaria contribute to the increasing number of orphans in Sub-Saharan Africa (UNICEF, 2006; Christian Alliance for Orphans, 2014). All these factors have strengthened the susceptibility of orphans in such a way that children are struggling for security, care, and protection (Makuu, 2017). Due to these factors, orphans and vulnerable children have been pushed into critical discrimination, stigmatisation, exploitation, abuse and general neglect from society (Save the Children, 2013).

\section{Psychosocial Services Provided to the Orphaned Children}

Psychosocial services involve services associated with creating connections between individuals and others in the community and society ("social") and how each person, adult or child, feels and thinks about him or herself and life ("psycho"). Therefore, the psychosocial services focus on aspects of orphans' lives, such as physical and material aspects, psychological, social, cultural and spiritual aspects. When providing psychosocial support, participation is one of the actual important elements to be involved since it builds orphans' sense of self and connections with one another and the community (REPSSI, 2009).

Various studies done in Tanzania showed that orphaned children residing in institutions were provided with food, clothes, soap, toothpaste, lubricant oils, powdered milk, medical care, uniforms and school fees, and accommodation. Others were provided with motivation, religious teachings, health services and educational support, while others were offered practical training courses like artwork, welding, masonry, carpentry and tailoring. Despite efforts by stakeholders (the government, international agencies, NGOs and individuals) for supporting orphans in the orphanages, most of the support is based on physiological needs, which have little contribution to the psychosocial wellbeing of orphaned children (Kichonge, 2007; Vedasto, 2008; Mchau, 2010; Juma, 2008; Makuu, 2019).

A study by Tadesse and Co-workers (2014) found that children suffered from a set of psychosocial problems that were least addressed in the orphanages. Thus, the study suggested interventions measures to promote the psychosocial wellbeing of those children. The interventions should focus on addressing psychological problems, improving socialisation skills, organising extracurricular activities, entertainment, and improving coping strategies. The psychological wellbeing of the orphaned children can be facilitated by psychological support, especially during times of suffering (Campbell et al., 2014). According to Caserta (2017), insufficient provision of psychosocial care is expected to have a severe impact on emotional wellbeing and mental health and some of them can be permanent. Positive psychosocial wellbeing is achieved when someone's emotional state and social relationship is predominantly healthy and adoptive.

\section{Psychological Factors Affecting Orphaned Children}

Children in the orphanages face problems in the area of psychological difficulties such as anxiety, depression, stress, anger, fear and sadness, loneliness, isolation, low self-esteem, stigma, poor social skills, discrimination and psychological disorders (Vedasto, 2015). For instance, the 
institutionalised orphaned children's care in Zanzibar was inadequate because of its failure to sustain the social and psychological needs of orphaned children. Such a stance was due to a lack of affection, attention, social networks, and security (Juma, 2008). UNICEF (2006) found that most of the psychological challenges facing orphaned children in the institutions resulted from limited funds, institutional environment, and ineffectiveness of caregivers in handling the psychological emotions of orphaned children.

Depression is another challenge that faces orphaned children when at the centres. According to Masmas et al. (2012), depression is a deep sadness with longtime harmful effects on the health and development of an individual. For instance, when parents die, children miss not only their physical presence but also many positive things they gave them when they were alive such as love, care and protection. In many instances, orphans and vulnerable children have no one to share the grief with, and this can compound their sense of helplessness. The lack of support during the grieving process and inadequate help in adjusting to an environment without their parents may lead to children becoming depressed.

According to Erango and Ayka (2015), there is a likelihood of orphaned children being affected by a high level of low self-esteem. This is due to lack of social and psychological support, poor parents' social life, and the death of parents. Psychological care such as the provision of good guidance and counselling, physical protection and mutual love are key to determining self-esteem. They added that there are other factors that determine the self-esteem of orphans; these are financial and material support and fellowship with other children. When parents live together before their death and reveal a strong relationship while having a considerable monthly income, the risk of being low in self-esteem will be decreased.

\section{Challenges Facing Caregivers}

President's Emergency Plan for AIDS Relief reported that the death of parents is a traumatic event to children, a tragedy that leaves the majority of orphans under severe depression, fear, worries, and anger. In due regard, trained caregivers are required to heal down wounds of children in the absence of their biological parents. The statistics show that about 80 percent of orphans in Sub Saharan Africa are cared for by caregivers who are too old and the majority being older women who also need care as well as comfort from their grandchildren and other society members (Regional Psychosocial Support Initiative (REPSSI, 2011).

It was further observed that challenges facing caregivers in the provision of services to the orphaned children in the studied institutions were quite different from those faced by the community. For instance, Vedasto (2015) found out that support to the orphaned children in the caregiver institutions experienced water shortage, inadequate modern cooking fuel, low payments and lack of time for leave. He argued that shortage of funds was the major limiting factor for inadequate payments of caregivers. The institutions depended on temporary donors in paying caregivers' salaries.

Furthermore, research conducted by Bettmann and co-workers (2015) on institutional care in Ghana found that orphans' institutionalised centre caregivers faced challenges when children went for the first time in the institutions. Children cried a lot and also, they became uncomfortable in the new environment and that aspect did the work to be tough for caregivers. Therefore, caregivers needed to be kind and careful in establishing as much as possible a solid bond with them. They further found that the caregivers understand the basic functions of taking care of the orphans at the orphanage centres, especially on emotional and interpersonal needs. However, the caregivers lack training and support, which were necessary for them to take care of the orphans especially attending to the emotional and interpersonal needs to ensure attachment.

\section{METHODOLOGY}

The study was conducted in six institutionalised centres in Ubungo Municipality in Dar-es-Salaam Region. It is one of the six Municipalities that constitute the city of Dar es Salaam. The area was chosen because it has many orphaned centres and a high number of orphans. According to the 2012 population census, the Municipality had a population of 845,368 where males were 409,149 while females were 436,219. The study had a sample of 67 participants who were selected

6| This work is licensed under a Creative Commons Attribution 4.0 International License. 
through the purposive sampling technique. They included twelve caregivers, six Directors, one and 48 children. The descriptive research design was used in the study because it accurately and systematically describes a situation or phenomenon. Data were collected through in-depth interviews and non-participant observation; they were sorted and coded based on themes and presented according to the research questions. Thematic analysis was used in qualitative data. Thematic analysis is the analysis that looks across all data to identify common issues that recur and identify the main themes that summarise all collected views from the study (Bricki and Green, 2007). This analysis allowed the researchers to put together meanings from statements of the informants within their particular perspective, as presented by Joffe and Yardley (2004). One advantage of thematic analysis is that it provides more outcomes when analysing interviews. This is because it is a flexible tool (Mohamed \& Rajab, 2016). The qualitative research approach was employed for the study because it provides a much more flexible approach and makes sense of reality. Kothari (2004) maintains that the qualitative approach emphasises the qualities, processes, and meaning that cannot be experimentally examined.

\section{RESULTS AND DISCUSSION}

The study investigated the psychosocial challenges facing orphaned children and caregivers in institutionalised institutions. The study had three questions. Data were collected through in-depth interviews and non-participant observation. Findings are presented according to research questions as follows:

Question 1: What are the psychosocial services provided to the orphaned children in the institutionalised selected centres?

Data for this question were collected through interviews from the orphan children, caregivers and the Directors of the institutions. Results showed that orphaned children were provided with food, educational materials, spiritual support, life skills, sports and games, health services, accommodation/shelter, and security. The most common foods provided in all centres were beans, rice, vegetables and stiff porridge. However, two centres out of six provided varieties of foods such as meat, fish, potatoes, eggs, chicken and fruits. These two centres were of high status compared to others in terms of resources despite the fact they had a high number of orphans.

The study investigated whether children were satisfied with the meals given. Findings showed that children from two centres were satisfied with the meals provided. Here is what one of the girls 'children from one of the institutions said:

"The caregiver provides us with stiff porridge, fried rice, beans, vegetables and potatoes. I am always satisfied with the food. I feel happy staying in this centre. I am enjoying my life despite the loss of parents."

One of the boys added:

"I am satisfied with meals provided by caregivers. Here, we eat beans, vegetables, rice, meat and stiff porridge. Our caregivers always make sure that food is available for us. I have never missed a meal since I joined this centre. The food is good and very nutritious."

However, results from four centres indicated that there were children who were not satisfied with the quality and portion of the meals given. Sometimes the portions given were not enough for them. One of the teenage girls said:

"We always accept the food we are given by the caregivers. For instance, we eat stiff porridge, rice and beans. We eat similar meals almost every day. We are tired of them. We want meat, chicken and chips."

Another girl added:

"Here, I am provided with varieties of foods such as rice, beans, bites, and vegetables, but sometimes the food is not enough, especially in the breakfast, but we share what is available because we live like brothers and sisters."

Results from the study concur with those of Mgeni (2013) that most of the food consumed at the institutions were rice, beans and stiff porridge. This is the reason for the children to complain. They wanted to eat various kinds of food, but they were not available. These findings imply that caregivers

7| This work is licensed under a Creative Commons Attribution 4.0 International License. 
and directors were trying their best to make sure that orphaned children were well-nourished despite the shortcomings. However, centres that provide quality and enough meals might have financial support from donors. Results from the study concur with those of Caserta (2017), who described the food as one of the physiological needs for children's survival and those other needs like love and belongingness, self-esteem and self-actualisation cannot be met until physiological needs are met.

The study also investigated whether children at the centres were supported in terms of educational materials. Results indicated that children were supported with various educational materials including exercise books, pens, pencils, books, mathematical sets, pocket money, school bags, and pairs of shoes, rubbers, sharpeners and school uniforms. For instance, twenty-seven children out of 48 (ninety percent) acknowledged having been provided with educational materials. Here is what two children from two different centres said, "We are provided with exercise books, pens, rulers, rubbers, sharpeners, shoes, pencils, school bags and uniforms. Other materials include caution and pocket money." A standard seven boy added, "I am happy I get all my school materials here. Some students have parents, but they do not have books like me. They borrow mine. I like staying here because I do not have any problem."

Results from this study contradict those of Vedasto (2015) that orphaned children residing in the institutions experienced a shortage of educational resources like school fees, textbooks, money for tuition and fare to and from schools. Such dissimilarity might be influenced by different geographical locations and times when the study was conducted. Furthermore, in 2016, the Tanzanian government passed the policy of fee-free education for primary and secondary school students that relieved caregivers with responsibilities for paying school fees and other monetary contributions.

Furthermore, findings disclose that four centres were faced with a shortage of educational materials. For instance, one of the caregivers said, "Some of my kids in standard one and two have tattered shoes and uniform. I feel sorry for them, but I do not have money to buy new ones. I always depend on good
Samaritans to help us." Another caregiver added, "Some of my children do not have exercise books and transport money. They walk a long distance to school. I feel sorry for them, but I have no alternative."

One of the directors added:

"We get educational materials from good Samaritans, but they are not enough. We have many children here. I am the director, but this does not mean that I have money to buy everything for all children. Most of the time, I depend on the communities around to help us. They are aware that children in this centre are orphans; therefore, they support us in various ways, but still, we have a shortage of educational materials."

From the findings, one can find that children were supported with educational materials differently and the reason being financial status. The information from the director relates to the Social Network Theory explained in this study that it operates from the family to the national level, which means that support to the orphaned children was provided by different people as one way of solving their problems.

Health care service was another area that the study focused on. The findings showed that all studied institutions had first-aid kits but not dispensaries/hospitals. However, children in three centres had NHIF cards which enabled them to access health services from nearby hospitals when they fell sick. Here is what one of the children said, "When I get sick, I go to the hospital for treatment. I do that because the centre does not have a hospital. I always use my NHIF card to cover my medical costs." However, there were children who did not have NHIF cards but got access to health care services through payment and were satisfied. This is what one of the children said:

"This centre is very good. We do not have a dispensary or hospital, but there is one nurse who looks after us when we get sick. She takes us to the hospital and pays for our treatment. I do not know where she gets the money. She works hard to make sure that we are provided with better health care." 
The findings showed that caregivers and the management at the centres ensured the children health-well-being. These efforts were taken to meet the children right as stipulated in the Act of 2009. The Children's Rights Act stipulates that health services are one of the rights of a child. This suggests the readiness of the individuals in the community who are always there to help when someone is in need. The implication here is that orphaned children are to be taken care of not only by the orphanage institutions but also by individuals around them so that they can also enjoy their rights like other children in the world. It is at this point where Social Network Theory applies.

The researchers examined whether the centres equip children with life skills. This is one of the aspects of instrumental support to children. Findings revealed that orphans were provided with some basic life skills training such as cooking, cleaning rooms, washing clothes and maintaining hygiene, selfesteem, responsibility and interpersonal skills. It was found that all centres provided opportunities for the children to engage in extracurricular activities to nurture their social skills. It was furthermore found that sometimes caregivers held sessions with the orphans' and taught them how to help each other. In some instances, the caregivers provided them with counselling services despite the fact that they were not trained to do so. The researchers are of the view that in order for life skills to be properly imparted to orphan children, there should be well-trained teachers to train them. Life skills prepare the young ones for the future life. Results from the current study relate to those of Msoka and Holroyd (2018) in the sense that orphans were assigned responsibilities, which developed their skills.

Spiritual service was another area the study paid attention to. Results from this study showed that children in all centres were provided with spiritual services. Religious leaders, both Muslims and Christians, visited centre a number of days per week. There was no specific religious leader who was assigned to the centres. One of the boys narrated, "Wednesdays and Saturdays are special days for worshipping and religious teachings." In one of the centres, children pray every day, that is to say, prayers were important for the children's spiritual growth. For instance, one of the girl children said, "We pray every day. We are also taught various prayers and good religious songs." It was found out that Muslim children were allowed to go to the Mosques on Fridays and Christians to the Churches on Sundays. From the findings, one can note that prayers and religious teachings were powerful in shaping and modifying children's behaviours. These results are similar to those of Fitzgerald et al. (2019) that the spiritual aspect is one of the measures for psychosocial wellbeing.

Furthermore, the study examined whether sports and games were practised by the children. Results indicated that children participated in various sports and games that included playing cards, football, music, netball, jogging, sliding, drawing, running, and designing objects. Sports and games were done on Saturdays and Sundays. Age and sex determined the type of game a child could play. However, younger children played simple games compared to older ones. Sports and games were important because they relieved children from unpleasant emotions such as stress, anxiety, depressions and anger. Subbarao and Coury (2004) argued that children participate in games and sports is important for their mental development as they assist in releasing stress and allows for better coping. Additionally, frequency of sports participation, performing team sports, performing outdoor sports, performing contact sports and involvement in the competition is associated with fewer internalising problems (Moeijis et al., 2018).

In another development, non-participant observation performed by the researchers showed that orphan children were provided with guidance and counselling but not as they should be. For instance, when children made mistakes, they were given verbal warnings but in a threatening way. Here is what one of the boys said during an interview: "Most of the time, caregivers correct us when we make mistakes. We are warned that if we will repeat the same mistakes, they will send us back home. We listen to them and follow what they want us to do because we have no choice. We get scared." Guidance and counselling are very important and significant, particularly to orphan children to mould behaviours on the one hand; on the other hand, to establish a good relationship between the caregivers and themselves but it must be provided correctly. From the findings, it can be said that caregivers had good intentions to take care of the children, but they

9| This work is licensed under a Creative Commons Attribution 4.0 International License. 
were not trained on how to counsel children. What they were practising was not guidance and counselling that would send a message of care and love but rather a threat that would contribute to fear and anxiety to the orphaned children. The importance of love and care to orphans has been emphasised by Pillay and Mwoma (2015) who pointed out that when caregiver shows love and care to orphans, it helps them to be resilient in the society. Therefore, love and affection are necessary elements in the provision of psychosocial services to orphaned children residing in the institutions.

Furthermore, researchers sought to establish accommodation status in the selected institutions. Accommodation is one of the important instrumental supports to orphans. The study found out that all children were properly accommodated and it was the role of the institutions to make sure that children were well accommodated. Accommodation is one of the basic needs that orphans need to be provided with. All centres had beds and mattresses. The rooms were well cleaned and the beds were properly spread. Children were separated between boys and girls. However, two of the centres had no security fences. Orphaned children need to be secured at the time of staying at the institutions for their future psychosocial wellbeing. Therefore, this is the call to the management to protect institutions by building security fences for the children's safety. The findings are similar to those of Mgeni (2013) who argued that every child has a right to feel safe and be protected from any situation or practices that result in a child being physically or psychologically damaged. Children reared in an insecure environment feel a lack of personal attention to them. As a result, their psychological health becomes affected.

Question 2: What are the psychosocial challenges facing orphaned children and caregivers in the selected centres?

Findings from the second question exposed that the caregivers were faced with various challenges that originated from the institutions and children themselves. For example, the unavailability of health insurance coverage to some children was a serious problem that hindered the provision of health care services at four centres. Here is what one girl child said: "I always get pain killers when I get sick before being taken to hospital. There is no hospital here. My caregiver tries different medications on me and only if I do not get better, she takes me to hospital." From the findings, one can note that the caregiver tried her best to help the child by using what she had at the centre, but on some occasions, she failed. This is because the orphan did not have health insurance. This result is similar to those of Chitiyo and co-authors (2008) and Kuo and Operario (2010) that health provision was one of the challenges facing the orphaned children and it was caused by financial constraints. Chitiyo and co-authors (2008) argued that during childhood, healthy psychological development is important for the future wellbeing of an individual.

Shortage of educational materials was another problem that faced children at the institutions. The study revealed that orphaned children in four institutions had a limited supply of educational materials such as exercise books, text and reference books. One secondary school-boy said:

"I am provided with a school bag, uniforms, pen, pencil, ruler and a pair of shoes for school, but some of the educational materials like textbooks and reference books are not available. Besides, I never get pocket money to meet other expenses."

Lack of access to educational materials denied orphaned children's access to better education since directors were not able to buy everything.

The poor attachment was another challenge that faced orphaned children. This was found in five centres where children experienced poor attachment from their caregivers. For instance, the aim of admitting orphans in the centres is to live together while supporting each other socially and psychologically under the caregiver's guidance. In this study poor attachment was caused by impolite/rude language used by the caregivers. A good example was illustrated by a teenage boy who said:

"One day, I was playing football. I failed to score a goal. My patron said that I am lazy like a woman. I felt bad and was shamed in front of my fellows. From that day I hate laying football. 


\section{I hate my patron as well. I do not like to be near} him."

In a situation like that, abuse of whichever type reduces the attachment level of orphaned children to their caregivers. The finding aligns with those of Msoka and Holroyd (2018) that regardless of the quality of the institution care, the need for face-toface interaction between the orphan and the caregiver is imperative. This attachment has a strong healing method to psychosocial disturbances faced by orphaned children.

Another challenge was children's laziness. This was found in two of the studied centres. Most of the children were not committed to work unless they were pushed. This was one of the aspects that disappointed caregivers. It was found out that the relationship between orphaned children and caregivers was good, but a serious challenge was laziness, especially to the children from seven years and above. They did nothing unless they were told to do things despite the fact that there were timetables that indicated daily routines. Information from the caregivers showed that some of the orphans were lazy right from their background. Therefore, laziness among children might be influenced by poor orientation, lack of advice and lack of guidance from their caregivers.

Shortage of water was another challenge that limited orphan children and caregivers to properly perform their duties like cleaning toilets and rooms, washing utensils and children's clothes. Water is an important need for any human being. During the interviews, it was noted that there were no water tanks and underground wells, which if built, could solve the problem. The implication here is, lack of such a significant need can result in the outbreak of diseases and failure to get other services. However, most of the areas in Dar es Salaam lack a reliable source of water.

\section{CONCLUSIONS}

The study concludes that orphan children in the study were provided with psychosocial services like food, shelter, educational materials, game and sports materials, care, guidance and counselling. However, there was a shortage of basic needs like water, quality and adequate food, health services and educational materials. The presence of caregivers who did not have guidance and counselling knowledge and skills negatively affected orphan children psychosocial wellbeing.

\section{RECOMMENDATIONS}

The study recommends the following: firstly, NGO's, stakeholders, community members and good Samaritans to continue supporting orphanages for the betterment of the orphaned children. Secondly, to educate the society/ communities around the centres on the importance of providing material support as well as visiting them regularly because that can inculcate in them a sense of humour, love and care. Visiting orphanage children enables them to feel part of the general community. The community has a big role to play in building up psychosocial wellbeing. This concurs with the central theme of Social Network Theory that is social ties. Thirdly, to engage children with social activities which mostly put orphans together rather than letting them isolated. This will improve the emotional support of orphans. The recommendations are in line with Snider (2006) that psychosocial wellbeing is achieved when there is a connection between the orphan and the adult caregiver as well as the maintenance of psychosocial health.

\section{REFERENCES}

Abebe, T., \& Aase, A. (2007). Children, AIDS and politics of orphan care in Ethiopia: The extended family revisited. Social Science and Medicine, 64 (10), 2058-2069.

Atwine, B., Cantor-Graae, F. \& Bajunirine, F. (2005). Psychological distress among AIDS orphans in rural Uganda. Journal of Social Science and Medicine, 61(3), 555-564.

Atwine, B., Cantor-Grace, E. \& Bujunirwe, F. (2021). Psychological distress among AIDS orphans in Rural Uganda. Social Science and Medicine, 61, 555-564.

Baaroy, J., \& Webb, D. (2008). Who are the most vulnerable? Disaggregating orphan categories and identifying child outcome status in Tanzania. Vulnerable Children and Youth Studies, 3(2), 92-101.

11| This work is licensed under a Creative Commons Attribution 4.0 International License. 
Beek, M., \& Schofield, G. (2004). Providing a secure base: Tuning in to children with severe learning difficulties in long-term foster care. Adoption \& Fostering, 28(2), 8-19.

Bettmann, J. E., Mortensen, J. M., \& Akuoko, K. O. (2015). Orphanage caregivers' perceptions of children's emotional needs. Children and Youth Services Review, 49, 71-79.

Boutin, J. L. (2006). An ounce of prevention: restructuring NGO street and vulnerable children programs in Tanzania (Doctoral dissertation, Doctoral dissertation, MA Dissertation, Boston University.

Brannon, L. (2008). Gender: Psychological perspectives (5th Ed). Boston: Pearson Education.

Bricki, N., \& Green, J. (2007). A guide to using qualitative research methodology. Retrieved August 20, 2021 from: http://fieldresearch.msf.org/bitstream

Campbell, C., Anderson, L., Mutsikiwa, A., Pufall, E., Scovdal M., Madauhire, C. Nyamukapa, C., \& Greyson S., (2014). Factors shaping the HIV competency of two primary schools in rural Zimbabwe. International Journal of Development: 10.1016/j.ijedudev.

Caserta, T. A. (2017). The psychological wellbeing of orphans and youth in Rwanda: Analysis of predictors, vulnerability factors and buffers. Publications of the Department of Social Science, Social Psychology: University of Helsinki, pp.226-236.

Chitiyo M, Changara DM \& Chitiyo, G. (2008). Providing psychological support to special needs children: A case of orphans and vulnerable children in Zimbabwe. International Journal of Education Development, 28:384-392

Christian Alliance for Orphans. (2014). Global orphans facts. Retrieved September 12, 2021 from http://www.christianalliancefororphans.or $\mathrm{g} /$ resources/orphans-fact.

Daniel, M. \& Runkundo, P., (2016). Children orphaned by AIDS in Uganda: Can they thrive under orphanage care? Social Work \& Society, 14(1), 1-17.

Eiroa-Orosa, F. J. (2020). Understanding psychosocial well-being in the context of complex and multidimensional. Int. J. Environ. Res. Public Health, 17(16), 5937.

Erango, M. A. \& Ayka, Z. A. (2015). Psychosocial support and parents' social life determine the self-esteem of orphan children. Risk Management Health Policy. 8: 169-173.

Evangelou, M. (2009). Early years learning and development: Literature review.

Golding, K. S., Dent, H. R., Nissim, R., \& Stott, L. (Eds.). (2006). Thinking psychologically about children who are looked after and adopted: Space for Reflection. John Wiley \& Sons.

Huynh, H. V., Limber, S. P., Gray, C. L., Thompson, M. P., Wasonga, A. I., Vann, V., ... \& Whetten, K. (2019). Factors affecting the psychosocial wellbeing of orphan and separated children in five low-and middle-income countries: Which is more important, quality of care or care setting? PLoS One, 14(6), e0218100.

Ismail, L. B., Hindawi, H., Awamleh, W., \& Alawamleh, M. (2018). The key to successful management of child care centres in Jordan. International Journal of Child Care and Education Policy, 12(1), 1-19.

Joffe, H. \& Yardley, L., (2004). Content and thematic analysis: Research methods for clinical and health psychology. California: Sage Publication.

Juma, S. K. (2008). Social and psychological problems facing orphaned children in Zanzibar: Papers in Education and Development, Vol. 28, 139-160.

Kamali, A., Seeley, JA., Nunn, AJ., Kengeya, KJF., Ruberantwari, A., Mulder, DW. (1996). The orphan problem: experience of a sub-Saharan Africa rural population in the AIDS epidemic. AIDS Care, 8 (5):509-516.

12 This work is licensed under a Creative Commons Attribution 4.0 International License. 
Kayombo, E. J., Mbwambo, Z. H., \& Massila, M. (2005). Role of traditional healers in psychosocial support in caring for the orphans: A case of Dar-es Salaam City, Tanzania. Journal of Ethnobiology and Ethnomedicine, 1(1), 1-7.

Kichonge, A. S. (2007). Towards improving care and support to in orphans Tanzania: The case of selected orphanage centres in Arusha region. Master Dissertation. University of Dar es Salaam, Tanzania.

Kothari, C.R. (2004). Research methodology. New Delhi: New Age.

Kuo, C., Operario, D. \& Cluver, L. (2010). Depression amongst carers of AIDS-orphaned and other-orphaned children in Umlazi Township. South Africa. Glob Public Health, 7(3), 253-269.

Larose S, Bernier A, Tarabulsy GM (2005). Attachment state of mind, learning dispositions, and academic performance during the college transition. Development Psychology 41(1):281.

Makuu, M. J. (2017). Family matters: Strengthening alternative care systems for orphans and vulnerable children in Dar es Salaam, Tanzania. Doctoral Thesis (Social work). Botswana, University of Botswana.

Makuu, M. J. (2019). Situation analysis of orphans and vulnerable children in existing alternative care systems in Dar es Salaam, Tanzania. Social Work \& Society, 17(1), 1-17.

Masmas, T. N., Jansen, H., Da Silva, D., Høj, L., Sandström, A. \& Aaby, P. (2012). Survival among motherless children in rural and urban areas in Guinea Bissau. Journal of Acta Paediatricia, 93(1), 99-105.

Mears, M., Singletary, J., \& Rogers, R. (2011). Strategies for supporting orphans and vulnerable children: An exploratory study of an exemplary model of care in Kenya. Child \& Youth Services, 32(4), 286-302.

Mchau, M. G. (2010). Adequacy of psychosocial care services provided to orphaned children by caregivers in Temeke District, Dar es Salaam Region, Tanzania. Master of Art (Applied Social
Psychology) Unpublished Thesis. University of Dar es Salaam.

Mgeni, W. (2013). Care practices for children living in orphanage centres in Morogoro and Dar es Salaam regions. Unpublished Master Dissertation, Sokoine University of Agriculture, Morogoro.

Mohamed, M., \& Rajab, M. (2016). Qualitative analysis methods. College of Business Technological: University Dublin.

Msoka, A. \& Holroyd, E. (2018). Children's perspectives of their psychosocial wellbeing in Tanzanian orphanages. International Journal of Nursing and Midwifery, 10(5), 41-46.

Murray, L. K., Skavenski, S., Kane, J. C., Mayeya, J., Dorsey, S., Cohen, J. A. \& Bolton, P. A. (2015). Effectiveness of trauma-focused cognitive behavioural therapy among traumaaffected children in Lusaka, Zambia: A randomised clinical trial. JAMA Pediatrics, 169(8), 761-769.

Ntuli, B., Mokgatle, M., \& Madiba, S. (2020). The psychosocial wellbeing of orphans: The case of early school leavers in socially depressed environment in Mpumalanga Province, South Africa. Plos One, 15(2), 1-17.

Nyawasha, T. S., \& Chipunza, C. (2012). An assessment of psychosocial and empowerment support interventions for orphans and vulnerable children in Zimbabwe. Journal of Human Ecology, 40(1), 9-16.

Pillay, J. (2016). Factors leading to orphans and vulnerable children living in community-based homes. Journal of Psychology in Africa, 26(6), 558-561.

REPSSI (2009). Mainstreaming psychosocial care and support through child participation psychosocial well-being series. https://www.forgood.co.za/cause/profile/repssiregional-psychosocialsupport-initiative.

REPSSI (2011). Psychosocial care and support for older careers of orphaned and vulnerable children: Policy guidelines. Nairobi: Help Age International.

13 This work is licensed under a Creative Commons Attribution 4.0 International License. 
REPSSI (2016). Psychosocial wellbeing for all ages. Johannesburg. https://www.forgood.co.za /cause/profile/repssi- regional- psychosocialsup port-initiative

Save the Children. (2013). Save the children's child protection strategy 2013-2015. Kingdom: Save the Children.

Schenk, K. D., Michaelis, A., Sapiano, T. N., Brown, L.\& Weiss, E. (2010). Improving the lives of vulnerable children: implications of horizons research among orphans and other children affected by AIDS. Public Health Rep., 125(2):325-336.

Scott, J. (1991). Social network analysis: A handbook. Sage Publications, Inc., Washington, DC.

Stover, J., Bollinger, L., Walker, N., \& Monasch, R. (2005). Resource needs to support orphans and vulnerable children in sub-Saharan Africa. Health Policy and Planning, 22(1), 2127.

Stroebe, M., Schut, H., Nauta, M. H. (2016). Is homesickness a mini-grief? Development of a dual process model. Clinical Psychology Science, 4 (2):344- 358.

Subbarao, K. \& Coury, D. (2004). Reaching out to Africa's Orphans: A framework for public action. Washington, DC: World Bank.

Tadesse, S., Dereje, F., \& Belay, M. (2014). Psychosocial wellbeing of orphan and vulnerable children at orphanages in Gondar Town, North West Ethiopia. Journal of Public Health and Epidemiology, 6(10), 293-301.

Fitzgerald, T., C., Millstein, R. A., Von Hippel, C., Howe, C. J., Tomasso, L. P., Wagner, G. R., \& VanderWeele, T. J. (2019). Psychological wellbeing as part of the public health debate? Insight into dimensions, interventions, and policy. BMC Public Health, 19 (1), 1-11.

UNICEF 2006). Care for children affected by HIV $\& A I D S$. New York: Research Centre.

UNICEF (2010). Children and aids program. United Republic of Tanzania.
UNICEF (2017). Press release, viewed at Retrieved August 30, 2021, from https://www.unicef.org/media/media_45279.ht $\mathrm{ml}$

Van Dyk, A. C. (2007). Occupational stress experienced by caregivers working in the HIV/AIDS field in South Africa. African Journal of AIDS Research, 6(1), 49-66.

Vedasto, V. (2015). The effectiveness of caregivers' psychosocial service provision to orphaned children: a case study of orphanages in Kinondoni municipality (Doctoral dissertation, University of Dar es Salaam).

World Bank. (2004). Most vulnerable children in Tanzania: Access to education and patterns of non-attendance.https://www.fhi360.org/sites/d efault/files/media/documents/Tanzania_Vulnera bility.pdf

Yang, H., Wu, Z., Duan, S., Li, Z., Li, X., Shen, M, \& Stanton, B. (2011). Living environment and schooling of children with HIV-infected parents in southwest China. AIDS Care 18(7):647-655.

14| This work is licensed under a Creative Commons Attribution 4.0 International License. 